\title{
REVIEW ON LATENT HEAT SOLAR AIR COLLECTORS
}

\author{
M. Selvaraj \\ Assistant Professor, Department of Mechanical Engineering, \\ Ganamani College of Technology, Namakkal, Tamil Nadu, India \\ P. Sadagopan \\ Professor, Department of Production Engineering, \\ PSG college of Technology, Coimbatore, Tamil Nadu, India \\ M. Vairavel \\ Research and Development Head, Tejatech Design Solutions, \\ Erode, Tamil Nadu, India
}

\begin{abstract}
Solar energy is employed by Solar air collectors. These collectors are simple devices to heat air. A typical solar air heater has the main parts such as glass cover, the panel, and the air duct. An air blower is included in the active solar system. An absorber plate is included in the air duct which is made up of wooden or metallic. The sides and bottom of the duct had been enclosed through the thermal insulation.
\end{abstract}

Keywords: Solar air collectors, Air duct, absorber plate, Thermal insulation, Active and Passive, PCM, Materials

Cite this Article: M. Selvaraj, P. Sadagopan, M. Vairavel, Review on Latent Heat Solar Air Collectors, International Journal of Advanced Research in Engineering and Technology (IJARET), 10 (6), 2019, pp 112-121.

$\mathrm{http}: / /$ iaeme.com/Home/issue/IJARET?Volume $=10 \& \mathrm{Issue}=6$

\section{INTRODUCTION}

An innovative method for distinguishing exceptional is the drying system. These systems are employed to preserve food. The applicable and advanced technology of food preservation is solar food dehydrator or dryers for maintainable growth. The first food preserving method is the drying which is employed by man, before cooking. The moisture is removed from the agricultural. So that the food product is stored for more time. The earliest way of drying is sun drying. In earlier days man rests the farm products in the sun over roofs, mats or drying flooring. But due to dissimilar climatic conditions like mist, wind, dust, and rain, the farm products are spoiled. There is a decrease in foodstuffs due to rodents, insects, and birds. These are the disadvantages of sun-drying. These are determined by good weather and quite a slow drying speed with the threat of mold growth thereby causing corrosion and decomposition of the produce. [1] have the efficiency of the solar thermal technology of air heaters is affected by the parameters such as length and bed height of collector, the type of the flat plate collector or absorber plate, wind rate or speed, glass cover and so on. Among these factors, 
the design of solar collectors considered the cover and the absorber plate or the flat plate collector are the most effective ones. [2-3] had considered The major heat is lost from a solar air collector which is in the form of normal, throughout the top of the cover. So that the systems' thermal efficiency is reduced. The heat transfer coefficient or film effectiveness which is low in nature among the air stream or airflow and the absorber plate or flat plate collector results in thermal effectiveness which is low in solar thermal technology of air heaters. Numerous studies had been made with the aim of raising the efficiency of a solar thermal collector by modifying the absorber plate or flat plate collector configuration. The wired mesh is considered an absorber plate. The direction of the airflow is increased by employing fin among the wire mesh inside the channel.[4-5] examined experimentally the effectiveness of the double and single-pass solar collectors through fins and layered wire mesh. The steel layered wire mesh which is seven in quantity were employed and the variety of the rate of MAF or mass airflow was among $0.038 \mathrm{~kg} / \mathrm{s}$ and $0.012 \mathrm{~kg} / \mathrm{s}$. At $7 \mathrm{~cm}$ distance, both the bottommost of the collector and the glass was employed in their study. According to their study, at $0.038 \mathrm{~kg} / \mathrm{s}$ of the rate of mass flow, the attained extreme efficiency for the double and single-pass air collectors was $63.74 \%$ and $59.62 \%$ respectively.[6-10] have designed an innovative pin-fin solar air collector combined through the absorber. So that the heat has vanished from the cover had been reduced and thermal efficiency is attained which is high in nature. In their design, at $5 \mathrm{~cm}$ distance, both the flat plate collector or the absorber plate and the glazing was employed. Based on their experimental results, for the volume of airflow of $19 \mathrm{~m}^{3} / \mathrm{h}$, the average of energy conversion or thermal efficiency of a solar collector with arrays of pin-fin reaches $50-74 \%$ than the $83 \%$ of solar energy transmitted by the glazing. [11-12] have examined the bed packed solar thermal technology of air heaters contain packed duct through blackened wire screen matrix collector. The dissimilar geometrical parameters, pitch, and the wire gauge diameter were performed. The effective efficiency is attained. As a result, the thermal or heat gain of bed packed solar collectors is comparatively higher than the smooth solar collectors. The pressure is dropped throughout the duct. In these cases, this pressure had been raised. [13] have Verified a single-glazed of matrix absorber solar thermal technology of air heater collector. The two sheets of black galvanized woven for the industrial purpose which are parallel to each other and a mesh is very fine with wire screens which are made up of copper is involved in these collectors. As a result, at the $4 \mathrm{~cm}$ height of the duct and the $0.04 \mathrm{~kg} / \mathrm{s}$ of the rate of the mass flow, the thermal efficiency or energy conversion of the solar thermal technology of air heaters was around 70\%.[14] have designed a solar thermal technology of air heaters in which the absorber plate or flat plate collector had been built through fins over it and the flowdirecting or obstructing vanes were attached to the fins. So that the turbulence had been created and the heat transfer area had been encompassed. In their design, at $5.5 \mathrm{~cm}$ distance, both the flat plate collector and the glass was employed and it was indicated that the efficiency of flow-directed or obstructed vanes solar thermal technology of air heaters is greater compared to flat plate air heaters without flow-directing or obstructing vanes and fins.[15] have examined the thermal effectiveness of a cross-corrugated or CC or chevron pattern solar air collector. The cross-corrugated or $\mathrm{CC}$ collector consists of an absorbing plate or flat plate collector which is wave-like and bottommost plate, which are positioned crosswise to form the airflow channel. In their study, the rate of mass flow or $\dot{m}$ changes in the variety among 0.25 and $0.001 \mathrm{~kg} / \mathrm{s}$. As a result, there is a monotonical rise in the effectiveness of collectors through $\dot{m}$. The higher rate of mass airflow is employed. So that better thermal efficiency or energy conversion of the solar air collectors had been attained. [16] Have examined numerous configurations of meshes which is a copper screen. The porosity and the surface area and the porosity are subjected through the taking every heat transfer into the account. [16-17] have employed double glazing over the solar collectors. So 
that the heat losses had been diminished throughout the topmost cover. So that there is an improvement in thermal efficiency. [18-19-20] have employed the identical procedure through this difference in their work. At the same time, the air was passing from directly above and underneath the flat plate collector or an absorber plate.[21] have analyzed a counterblow or the flow of a fluid in opposite directions of solar thermal technology of air heaters for cold climate. [22] have examined a double or two passes solar thermal technology of air heaters without and with considering the porous media or material in the lower channel so that the efficiency of the declared solar thermal technology of air heaters through porous media or material had been exceeded by 75\%. [23] Have examined an unglazed solar air pre-heater which consists of perforated furrows and ridges siding. So that the wind flow velocity had been subjected through the effectiveness of the unglazed solar thermal technology of air heaters. At $2 \mathrm{~m} / \mathrm{s}$, the efficiency is attained for $65 \%$ of wind flow velocities and at $7 \mathrm{~m} / \mathrm{s}$, the efficiency is dropped below for $25 \%$ of wind flow velocities.[24] have Experimental study over the perforated flow-directing or obstructing vanes through numerous open or free area ratio in a rectangular duct. A system that is the same as a solar thermal technology of air heaters was exposed that the best performance is attained for the flow-directing or obstructing vanes through $46.8 \%$ of open or free area ratio. A large area of land is employed for these processes and takes more time and labor-intensive highly. The advanced development in the cultures and industries leads to artificial mechanical drying. These processes are energyintensive highly and more expensive which increases product cost ultimately.[25-26] Recently, so many efforts are employed to improve "sun drying". But these improvements lead to "solar saturated drying". In the solar drying method, the drying process is carried out through solar dryers or specialized devices and the farm produce is protected from damage through insect pests, dust, and rain. By comparing to natural "sunlight dries", solar dryers or devices generate temperature which is higher, $\mathrm{RH}$ or relative humidity which is lower, and moisture in product content which is lower. So that the spoilage had been decreased during the manufacturing drying process. Thus, solar saturated drying is the best method for drying process compared to artificial mechanical drying and natural drying. The planet's energy and food crises are attained through the solar dryer or specialized devices. The farm produce had been preserved mostly through drying. And these employ solar dryers more effectively.

\section{CLASSIFICATION OF SOLAR DRYERS}

Solar dryers are categorized into Direct, Indirect and Combined mode. These are illustrated in a review paper 1 .

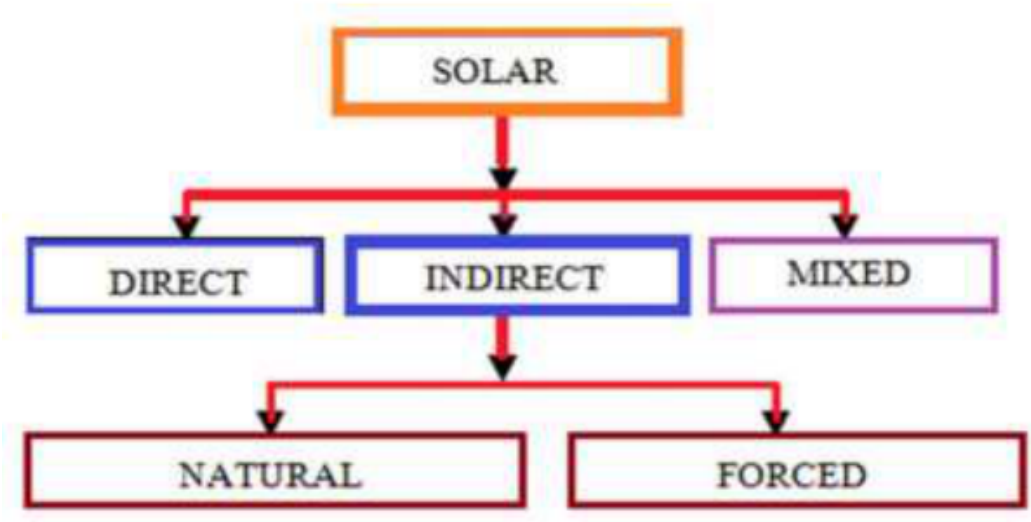

Review Paper 1: Classification of Solar dryers [25] 


\subsection{Direct Solar Dryers}

Drying are employed by Food product. A convective loss had been reduced through the glass cap. These solars direct to the surroundings and raise the temperature in the interior of the dryer. Dryer employs direct radiation from the sun [26]. A cover that is transparent is employed to transmit radiation. The glass is acted towards as a cover and the incident.

\subsubsection{Cabinet Type Solar Dryer}

Cabinet Type Solar Dryer is shown in the review. Usually, these are a small box and wood is employed to construct these boxes and having the ratio among the width and the length is three approximately. The dull black color is employed to paint the bottommost of the cabinet and all the inner sides. So that solar radiation is absorbed and the glass cover is employed to transmit these solar radiation. [27] Have the heat energy had been absorbed due to the black interior surface. Both the upper and bottom of the dryer has the holes. So that in the cabinet, proper air ventilation had been consumed.

\subsubsection{Staircase Solar Dryer}

[28] Have Split into 3 equal segments. These 3 compartments had been gain access from the swing within the dryer. The aluminum or stainless steel trays are employed to collect the food products which is to be dried and it uses wire mesh in the base and which is subjected to solar power. The wave solar power which is very long had been trapped. So that there is a rise in the dryers' temperature. In the food item, these leads to evaporation of moisture. The uppermost end of this drier has a chimney. So that moist air present in the cupboard is removed. The air entrance is permitted in the cupboard by creating four holes in the bottommost of the drier. [29] Have the partition is employed to divide among compartments. The airflow is permitted through the same variety of air pockets which is available in these compartments. It's shaped exactly as same as the metallic staircase. The galvanized sheet metal which is two walled is employed to fur the crosswise and lowermost of the dryer. The sandwiched cavity which is constructed through glass wool is employed to surround for insulation. So that the heat losses through convection are reduced. A transparent plastic or glass sheet is employed to fur the drier surface. So that solar radiation is permitted to pass through and be trapped indoors. The cable mess and 3 shelves are presented in the dryer. So that the food item had been loaded. At the top, the translucent glazed surface is designed.

\subsubsection{Solar Dryer with Glass Roof}

This dryer has two glass roofs which are long. These are associated with the span laterally. So that the cabinet is covered. These roofs inclined at the path of the north-south. [30] have A hood cap is provided at the top of roofing. The slot which is situated longitudinally is employed by these caps. So that the moist air is removed. The gap is generated among the atmospheric atmosphere and the cabinet due to stress. The fresh air under the atmospheric condition is sucked in through holes, which can be found on both walls. Below the drying system, these holes are generally facing towards the west and west. So that the uniform airflow is observed. The energy is consumed by painting black color to trays and the inner wall. The air which is said to be fresh condition had been entered into the dryer from walls. The lower portion of the wall has these air i.e directly above the drying platforms and underneath the glass roof. The temperature inside the cupboard and the air circulation had been controlled through these activities. so that(many times comes) food products had been isolated consistently over the trays. The solar radiation is employed to heat these trays and these heats are transmitted through the glass. So that there is an increase in the interior temperature. 


\subsection{Indirect Type of Solar Dryer}

[31] Have Immediate Kind of Solar Dryer's drawbacks is defeated through the Indirect Kinds of Solar Dryers. The two distinct kinds of Indirect Solar Dryer are discussed in detail. Those are Organic convection or circulation of Air and Forced convection or circulation of Air.

\subsubsection{Solar Dryer with Natural Convection}

[32] Have natural convection or mode of heat transfer is employed to design an airflow motion and to collect heat through the device or a solar collector. These are moved into the dryer chamber. These working hot fluids had been employed to heat the food products, which is present in the drier. The moisture had been migrated because of the flow motion of warm air, which is present inside the products. And also there is a disappearance of free moisture which is present over the surface and flows from your dryer by the capability of a fluid that is present in a system to circulate hot air continuously.

\subsubsection{Natural Convection Solar Dryer with Chimney}

Natural Convection Solar Dryers with Chimney, which is normally called a passive kind of device or Solar Dryer. Both the device which is employed for solar hot water heating and room employed for drying had been connected directly and at top of the drier, there is a chimney. [33] Have A copper flat plate that is painted darkly is employed in the solar collector and works as an absorber. At top of these plates, there is a cover which is transparent. These establish the passage to the airflow. The heat losses had been reduced from the external bottom of the collector plate. So that the base of the collector had been insulated. One end of this collector is stored open to the atmosphere laterally through the other end which is connected to the bottom of the drying room. A block of wood is employed to construct these rooms. The black color paint is employed to paint the inner surface of the chamber. So that the extreme quantity of heat had been attained which is supplied to it. At the top of the chamber, there is the chimney. So that the upward force had been raised which is collected over the airflow. [34] Have inside the chamber, there is an increase in the velocity of airflow because of these arrangements. So there is a fall in the pressure. The Organic Circulation had been caused through the formation of a pressure gradient inside the dryer and also away from the dryer. The foodstuff which is to be dried out is placed over the noncorrosive metal trays, which situated in the chamber. By comparing shade drying, there is a $73 \%$ decrease in the rate of drying in the technologically advanced drier.[35] have Organic Convection Solar Drying System is applicable for drying of berries as well as for drying numerous agricultural food items and vegetables efficiently through their technologically advanced installation. These are published in 2002 of the calendar year. In their analysis, the Natural Convection Flat Plate air heater or3 Solar Dryer is employed to dry the Thompson or oval seedless grapes. The qualitative analysis was made among the traditional drying methods of Open Sun and Shade Drying. As a result, the grapes are dried in these drying are seven and 15 times respectively, the grapes were dried in just 5 days using the developed Solar Dryer and raisins which is high-quality had been produced.[36] Have examined and compared the solar grape drying with Greenhouse and Open Sun drying. As a result, Solar Drying was economically applicable compared to other categories of drying was founded. The drying of Sultana or oval seedless grapes through three dissimilar drying procedures had been compared and established. [37] have detected that the time required to wash the blossoms with a new kind of living environment or tunnel kind green home was almost the same when compared with solar dryer with natural convection. But it was remarked that overall, the Greenhouse Tunnel Dryer had performed better than the Natural Convection Open Sun Dryer and Solar Dryer. 


\subsubsection{Forced Circulation Type}

[38] have Unlike the Natural Convection Solar Dryer in the event of Forced type Solar Dryers, the working fluid is circulated forcefully throughout the system, which is present among the collector inlet and dryer outlet.[39] have the force flow of the air is established through the machine. A blower or fan is employed to operate through the conference or nonconventional source of energy.

\section{FORCED CONVECTION FLAT PLATE SOLAR DRYERS WITH OBSTACLES}

An increase in the temperatures of working fluid in these systems results in the thermal effectiveness of the solar thermal collector which is higher than the other kinds. Forced Circulation of working fluid had been employed in the absorber plate or flat plate collector. A thin coated Forced Convection Solar Dryer or specialized device is employed to attain Solar drying experiments for food products that are to be dried. An auxiliary heater along with solar collector has been also utilized in the experimentation. The food product is dried in the ambient or air temperature ranges among $32{ }^{\circ} \mathrm{C}$ and $36{ }^{\circ} \mathrm{C}$ and the dryer temperature was listed as $45^{\circ} \mathrm{C}$ into $70^{\circ} \mathrm{C}$. As a result, at a minimum speed of drying, the food products are dried. The drying air temperature is employed to reduce the drying speed. The features of the drying curve determine these speeds. The applicable experimental data had been attained by analyzing the twelve advanced mathematical models. [40] Demonstrates the experimental arrangement. The experimental evaluation had been carried out through the sample of an Indirect Type Solar Dryer or specialized device with a special type of heat transfer or Forced Convection. The employed speed of the working substance or fluid is between $1 \mathrm{~m} / \mathrm{s}$ and 1.4 $\mathrm{m} / \mathrm{s}$. Numerous experiments were performed. So that the 3 dissimilar flux modes of operations had been attained. A device was mounted in the production of the collector. So that the 3 dissimilar modes like the Licking, the Cross-Flow and the Mixed Mode are developed manually. It had been observed that alter of more than $8{ }^{\circ} \mathrm{C}$ in temperatures over numerous trays in Crossing Mode when compared with the Licking Mode, where no difference was listed. The local material is employed to assemble the total setup. The temperatures that range between $40^{\circ} \mathrm{C}$ and $69^{\circ} \mathrm{C}$ at the drying room was attained for each mode of airflow on each tray. The performance of crop drying had been improved through solar dyer. By comparing the results of flat plate collector without and with considering the tracking. The collector had been developed in experimental electrical equipment. So that the experiments are conducted on it. Both the data of the tracked and fixed conditions of the absorber plate or flat plate collector was collected. It had been observed that the outlet temperature raised for $4^{\circ} \mathrm{C}$. A tracking mechanism is employed in collector efficiency at a profit of 5-7 percent. An avocado drying employs a Forced Convection Type Solar Dryer through the assistance of plate rough and smooth solar thermal collectors. The work of their development of drier considerations was clarified in detail. The rough and the smooth plate collector are employed for dissimilar experiments. The result attained through these experiments is employed to compare the performance of the system. The thermal effectiveness of a solar collector which is poor is attained through the low heat transfer rate by convection and by the absorber plate or flat plate controller to working fluid or substance. A synthetic rib roughness over the bottommost was provided into the flat plate controller or absorber plate. With this system, it was discovered that the film coefficient was increased considerably. The absorber plate temperature was discovered to $69.2^{\circ} \mathrm{C}$, which was attained through the extreme air temperature from the drier room to $64.1^{\circ} \mathrm{C}$ under no-load condition. The grapes of $3 \mathrm{~kg}$ were dried between $81.4 \%$ of the first amount of moisture and $18.6 \%$ of the Final amount of moisture. The same amount and same quality of grapes are dried within 8 days in Open Sun Drying. The sample dryer had 
been developed to attain a $1.03 \mathrm{~m}$ of an extreme collector region. As a result, solar dryer with rough plate collector employed for drying grapes gives better performance than a smooth plate collector. An innovative sort of effective device or solar dryer had been developed and tested exclusively for drying fruits. The Forced Air Circulation arrangement is employed to develop the Flat Plate Solar Dryer system. So that the extreme solar power had been consumed. The sensible heat of the granite sheet was used as heat storage material. Forced Circulation of Air is produced by using the air blower which is placed in the air inlet. The absorber plate or flat plate collector temperature was recorded to $77^{\circ} \mathrm{C}$ under no-load requirements through the extreme air temperature at the dryer was found $41 \circ$ C. $2 \mathrm{~kg}$ of grapes were dried between an $80 \%$ of First amount of moisture and the $6 \%$ of Final amount of moisture over 36 hours. The collector surface has an inclination of a particular angle that was subjected to the place, to consume maximum solar power. The detailed analysis has been completed, without and with considering the outcomes and the thermal storage medium. The decrease in the drying time results in a rise in the rate of moisture elimination through the thermal storage material. The thermal effectiveness analysis of the ETC solar air heating system had been recognized. The operation had been improved by inserting the aluminum tube into each and every evacuated tube. Numerous experiments were progressed by employing Forced Air Circulation which is made through air mill. It had been noted that the reflector with a higher oxygen flow rate ie employed to attain the thermal effectiveness of the system. These were almost double when compared to the thermal effectiveness of the program without using a reflector and at a very low oxygen flow rate. It was also recorded that the highest temperature variance among the outlet and inlet atmosphere of $65.8^{\circ} \mathrm{C}$ together with the use of the reflector. This long wave radiation has trapped inside the systems creating the greenhouse effect. Due to this effect, the temperature within the room can rise up to $20^{\circ} \mathrm{C}$, over ambient air temperature. This heated air inside the drying chamber extends through the trays piled and evaporates the moisture of food products. These forms of systems are applicable for large scale manufacturing, with relatively low drying temperature. Review paper 8 shows a simple solar air flat plate collector system using forced convection method used for food merchandise drying. In this system, obstacles are placed in the solar collector and air compressor is used to make force convection of fluid. In this system, the blower is employed to drive the airflow or fan fitted at the inlet of a solar collector. The absorber plate is made up of aluminum sheets painted with black paint to absorb maximum solar energy falling on it. The surface of the absorber is made with some small barriers into the air stream, reducing the airspeed inside the collector.

\section{SUMMARY}

During the literature survey, the furthermost significant focus of these research works was the practical adaptability. It was noticed that the experiments are completed under a known and controlled atmosphere. But in practice, the environmental conditions like, temperatures, relative humidity, etc., may vary with time. So that the mistakes had been generated while commercializing the research work. In this study work, this aspect is kept at a significant level and hence drying is done under the uncontrolled Environmental measurement requirements. A selective overview of available literature in the field brings out an important concern related to the distinct technique utilized for solar grape drying using FDS solar system. The openings in the literature with regard to developing a prototype solar FDS food dryer using Forced Air Circulation Systems also have come to the force. The present work is an effort in the direction of developing an efficient and economical food washing machine, by using solar energy. 


\section{REFERENCES}

[1] G. O. G. Lof and R. A. Tybout, "Cost of house heating with solar " energy," Solar Energy, vol. 14 , no. 3, pp. 253-278, 1973.

[2] S. K. Roy and H. Liu, "Solar heating," in Wiley Encyclopedia of Electrical and Electronics Engineering, John Wiley \& Sons, New York, NY, USA, 1999.

[3] T. Tanaka, T. Tani, S. Sawata, K. Sakuta, and T. Horigome, "Fundamental studies on heat storage of solar energy," Solar Energy, vol. 19, no. 4, pp. 415-419, 1977.

[4] K. N. Mathur, "Heat storage for solar energy space heating," Solar Energy, vol. 6, no. 3, pp. 110-112, 1962.

[5] A. Abhat, "Short term thermal energy storage," Revue de Physique Appliquee' , vol. 15, no. 3 , pp. 477-501, 1980.

[6] I. Dincer and S. Dost, "A perspective on thermal energy storage systems for solar energy applications,” International Journal of Energy Research, vol. 20, no. 6, pp. 547-557, 1996.

[7] E. Mohseni-Languri, H. Taherian, R. Masoodi, and J. R. Reisel, "An energy and exergy study of a solar thermal air collector," Thermal Science, vol. 13, no. 1, pp. 205-216, 2009.

[8] O. Lalude and H. Buchberg, "Design and application of honeycomb porous-bed solar-air heaters," Solar Energy, vol. 13, no. 2, pp. 223-242, 1971.

[9] J. J. Jurinak and S. I. Abdel-Khalik, "Sizing phase-change energy storage units for airbased solar heating systems," Solar Energy, vol. 22, no. 4, pp. 355-359, 1979.

[10] S. Sillman, "Performance and economics of annual storage solar heating systems," Solar Energy, vol. 27, no. 6, pp. 513-528, 1981.

[11] A. E. Saez and B. J. McCoy, "Dynamic response of a packed bed thermal storage system-a model for solar air heating," Solar Energy, vol. 29, no. 3, pp. 201-206, 1982.

[12] N. K. Bansal, A. Boettcher, and R. Uhlemann, "Performance of plastic solar air heating collectors with a porous absorber," International Journal of Energy Research, vol. 7, no. 4, pp. 375-384, 1983.

[13] M. S. Sodha, S. K. Bharadwaj, and A. Kumar, "Investigations on an air-heating system having thermal storage," Energy Conversion and Management, vol. 24, no. 4, pp. 297303, 1984.

[14] A. K. Bhargava, H. P. Garg, V. K. Sharma, and R. B. Mahajan, "Investigation on doubleglazed solar air heater connected in series with rock bed solar collector-cum-storage system," Energy Conversion and Management, vol. 25, no. 2, pp. 139-146, 1985.

[15] H. P. Garg, V. K. Sharma, G. Datta, and A. K. Bhargava, "Functional aspects of a porous bed solar air heater," Energy, vol. 11, no. 9, pp. 913-923, 1986.

[16] S. P. Sharma, J. S. Saini, and H. K. Varma, "Thermal performance of packed-bed solar air heaters," Solar Energy, vol. 47, no. 2, pp. 59-67, 1991. 
[17] G. Rizzi and V. K. Sharma, "An inexpensive solar collectorstorage system for space heating-I. Design methodologies," Solar and Wind Technology, vol. 7, no. 4, pp. 447$455,1990$.

[18] "Solar manual, section-3, detailed design of storage subsystem design (A/C)," ASHRAE, 1998.

[19] I. Abbud, G. O. G. Lof, and D. C. Hittle, "Simulation of solar air heating at constant temperature," in Proceedings of the American Solar Energy Society Annual Conference, Washington, DC, USA, April 1993.

[20] H. E. S. Fath, "Thermal performance of a simple design solar air heater with built-in thermal energy storage system," Energy Conversion and Management, vol. 36, no. 10, pp. 989-997, 1995.

[21] P. M. Chauhan, C. Choudhury, and H. P. Garg, "Comparative performance of coriander dryer coupled to solar air heater and solar air-heater-cum-rockbed storage," Applied Thermal Engineering, vol. 16, no. 6, pp. 475-486, 1996.

[22] S. Aboul-Enein, A. A. El-Sebaii, M. R. I. Ramadan, and H. G. El-Gohary, "Parametric study of a solar air heater with and without thermal storage for solar drying applications," Renewable Energy, vol. 21, no. 3-4, pp. 505-522, 2000.

[23] S. O. Enibe, "Performance of a natural circulation solar air heating system with phase change material energy storage," Renewable Energy, vol. 27, no. 1, pp. 69-86, 2002.

[24] N. S. Thakur, J. S. Saini, and S. C. Solanki, "Heat transfer and friction factor correlations for packed bed solar air heater for a low porosity system," Solar Energy, vol. 74, no. 4, pp. 319-329, 2003.

[25] K. Abbaspour-sani, "Sizing of a packed bed storage for solar air heating systems," International Journal of Engineering Transactions B, vol. 16, pp. 155-162, 2003.

[26] K. Abbaspour-sani, "Sizing of a packed bed storage for solar air heating systems," International Journal of Engineering Transactions B, vol. 16, pp. 155-162, 2003.

[27] H. H. Ozt " urk and Y. Demirel, "Exergy-based performance " analysis of packed-bed solar air heaters," International Journal of Energy Research, vol. 28, no. 5, pp. 423-432, 2004.

[28] P. Naphon, "Effect of porous media on the performance of the double-pass flat plate solar air heater," International Communications in Heat and Mass Transfer, vol. 32, no. 1-2, pp. $140-150,2005$.

[29] X. Wang, J. Liu, Y. Zhang, H. Di, and Y. Jiang, "Experimental research on a kind of novel high temperature phase change storage heater," Energy Conversion and Management, vol. 47, no. 15-16, pp. 2211-2222, 2006.

[30] A. A. El-Sebaii, S. Aboul-Enein, M. R. I. Ramadan, and E. ElBialy, "Year round performance of double pass solar air heater with packed bed," Energy Conversion and Management, vol. 48, no. 3, pp. 990-1003, 2007.

[31] M. M. Alkilani, K. Sopian, S. Mat, and M. A. Alghoul, "Output air temperature prediction in a solar air heater integrated with phase change material," European Journal of Scientific Research, vol. 27, no. 3, pp. 334-341, 2009. 
[32] S. B. Prasad, J. S. Saini, and K. M. Singh, "Investigation of heat transfer and friction characteristics of packed bed solar air heater using wire mesh as packing material," Solar Energy, vol. 83, no. 5, pp. 773-783, 2009.

[33] R. Singh, R. P. Saini, and J. S. Saini, "Models for predicting thermal performance of packed bed energy storage system for solar air heaters - a review," The Open Fuels \& Energy Science Journal, vol. 2, pp. 47-53, 2009.

[34] P. T. Saravanakumar and K. Mayilsamy, "Forced convection flat plate solar air heaters with and without thermal storage," Journal of Scientific and Industrial Research, vol. 69, no. 12, pp. 966-968, 2010.

[35] V. V. Tyagi, A. K. Pandey, S. C. Kaushik, and S. K. Tyagi, "Thermal performance evaluation of a solar air heater with and without thermal energy storage," Journal of Thermal Analysis and Calorimetry, vol. 107, no. 3, pp. 1345-1352, 2012.

[36] D. L. Zhao, Y. Li, Y. J. Dai, and R. Z. Wang, "Optimal study of a solar air heating system with pebble bed energy storage," Energy Conversion and Management, vol. 52, no. 6, pp. 2392-2400, 2011.

[37] M. M. Alkilani, K. Sopian, M. A. Alghoul, M. Sohif, and M. H. Ruslan, "Review of solar air collectors with thermal storage units," Renewable and Sustainable Energy Reviews, vol. 15, no. 3, pp. 1476-1490, 2011.

[38] Ruban Murugesan, Dr. Sivaganesan Selvaraju and Dr. C.Dhanasekaran, Computational Fluid Dynamic Analysis and Experimentation on Solar Desalination System Used Different Latent Heat Materials, International Journal of Mechanical Engineering and Technology, 9(3), 2018, pp. 1068-1080.

[39] V. Dubovsky, G. Ziskind, and R. Letan, "Analytical model of a PCM-air heat exchanger," Applied Thermal Engineering, vol. 31, no. 16, pp. 3453-3462, 2011.

[40] Ajeet Kumar Rai and Vivek Sachan and Maheep Kumar, Experimental Investigation of a Double Slope Solar Still with a Latent Heat Storage Medium, International Journal of Mechanical Engineering and Technology (IJMET), Volume 4 Issue 1 January- February (2013), pp. 22-29

[41] P. Dolado, A. Lazaro, J. M. Marin, and B. Zalba, "Characterization of melting and solidification in a real-scale PCMair heat exchanger: experimental results and empirical model," Renewable Energy, vol. 36, no. 11, pp. 2906-2917, 2011.

[42] G. Murali, G. Sandeep, N. Hari, M. Praveen and B. Neeraj, Experimental Studies on Solar Aluminium Can Air Heater With And Without Latent Heat Storage, International Journal of Mechanical Engineering and Technology, 9(4), 2018, pp. 145-155.

[43] M. M. Alkilani, K. Sopian, and S. Mat, "Fabrication and experimental investigation of PCM capsules integrated in solar air heater," American Journal of Environmental Sciences, vol. 7, no. 6, pp. 542-546, 2011.

[44] P. Charvat, M. Ostry, T. Mauder, and L. Klimes, "A solar air collector with integrated latent heat thermal storage," EPJ Web of Conferences, vol. 25, article 01028, 2012. 